The Geneva Papers on Risk and Insurance, 23 (No. 88, July 1998), 318-330

\title{
A 25 Years (and more) in Reinsurance Looking Back and Looking Forward*
}

\author{
by Fedor Nierhaus**
}

Dr. Klaus Gerathewohl (1928-88), my admired mentor in reinsurance, may have been the last one in this industry to have made the attempt to reconcile the manifold aspects of the reinsurers' day-to-day practice with the theoretician's vision of our business. When his (and some of his colleagues' - I was not yet amongst his cooperators) magnum opus "Reinsurance - Principles and Practice" was written, which appeared in 1976 and 1979, our world of insurance and reinsurance was no longer as simple as before. But it was still far away from the complexity in which it appears today. Until his untimely death, Klaus Gerathewohl, in collaboration with many of his colleagues (amongst them since the midseventies now also myself) ventured again and again to interpret and influence this world of reinsurance in contributions to books, in articles and speeches. He would, had he lived longer, have continued this role as active participant and commentator. Let me, in his memory, and also near to the end of my own active involvement in reinsurance, attempt a look backwards and a look forwards: To see where our increasingly complex reinsurance and insurance world - the latter not looked at as such, but as the reinsurer's base and environment - comes from, where it is today and in which direction it might go.

A historical look backwards over more than 25 years of reinsurance (for me actually 35 ) would be tempting. I, however, believe that such a perspective would not adequately reflect the "paradigmatic" changes during this period, which need to be seen in order to conclude from them the resulting effects on the demand and supply of reinsurance or, more in today's terminology, on the added values demanded from and offered by reinsurers.

The three really fundamental changes which affected reinsurance - and insurance - in this period and ultimately were behind almost all of what has changed since then, were,

\footnotetext{
* In memory of Klaus Gerathewohl

** Member of the Board of Management, Munich Reinsurance Company, Munich.
} 
and this is not meant to be surprising, (1) the increased relative weight of investment results as compared with the underwriting results, (2) the globalization of our industry and (3) the process of deregulation worldwide in financial services as a whole, not only insurance.

\section{Looking Backwards: Where are We and Where do We Come From?}

\subsection{Firstly: The increased weight of investment results as against underwriting results}

The oil crises after 1973, which affected economies worldwide in an unprecedented way, led to what was then called stagflation, that is simultaneously inflationary and stagnating economies. As a consequence the oil crises also led to unprecedently high nominal and real interest rates (the latter reflecting changed credit risks). This dramatically increased the income insurers derived from investing their underwriting reserves. Moreover, in the industrial world the latter continually increased, reflecting the faster growth of highly reserved liability insurance as compared with lower reserved property insurance.

This changed the balance between the underwriting results on the one hand and the investment returns on the other, and had considerable effects on our industry and our business.

- Insurers could incur much higher negative underwriting results and still show positive operating results.

This made market underwriting results in many industrial countries develop in the direction of at best marginally positive, if not almost permanently negative: in other words, it led to almost permanent market combined claims and cost ratios of above $100 \%$ in many fields.

- This new situation tempted many into what was critically called "cash-flow underwriting", which actually, to be fair, was a misnomer for what was really being aimed at: namely higher "bottom line" results and not just more cash-flow.

- The term "bottom-line" implies also that to increase market share and thereby achieve better overall results, many insurers and reinsurers increasingly became prepared to neglect line profitability in favour of multiline, across-the board overall profits after costs and investment returns - and after reinsurance or retrocession.

- The higher or lower investment earnings potential of the different classes of insurance were consequently taken into account more than before by insurers in their decisions as to how much risk to retain and how much to reinsure: Highly reserved and thus - after investment income still sufficiently profitable lines of business (particularly if not exposed to large losses) were reinsured to a decreasing extent (or perhaps only for different reasons such as capital or surplus requirements). Lines of business that were not sufficiently profitable overall - after investment income - and usually lower reserved (such as short-tail property, particularly if exposed to large losses) were reinsured to a larger extent.

- In the last decade the likely investment income from a reinsured portfolio, if significant, has increasingly been taken into account by the reinsured and his reinsurer when 
calculating reinsurance prices. In "financial" reinsurance the financial aspects are usually expressly taken into account through the inclusion of interest income in the agreed pricing formula.

- In view of the much larger weight of investment results as compared with underwriting results it makes increasingly less sense to look at "underwriting (results) cycles" rather than "operating (results) cycles" for guidance as to where the industry stands. This is supported by the fact that soft downward cyclical phases only "turn" into harder cyclical phases when operating results and not just underwriting results become marginal or negative (and this not only due to one or more major losses or catastrophes but also without the help of such extraordinary events).

It is often said that the cyclical downward phases have become longer and the upward ones shorter. This is true, but gives a wrong impression: it is only the downward phases of the underwriting (and not the operating) cycle which have become longer and its upward phases shorter. But considering that the underwriting cycles are increasingly meaningless, it is important and necessary to see much longer positive phases in the "operating (results) cycle" than marginal or negative ones: for it is these positive phases which we of course need to earn adequate returns over reasonable periods.

- In this context it will be interesting to see what impact the "shareholder value" concept will have, which, even if not new in what it means, is increasingly determining the thinking of shareholders, capital markets, fund managers and thus the managers of stock companies. Marginal or negative operating results affect the return on equity to be earned on an annual and multi-annual basis. Most larger insurers and reinsurers will have internal (or even externally published) return on equity objectives (usually based on internal equity - i.e. risk capital-allocations). These return-on-equity objectives, if jeopardized by marginal or negative operating results, might lead to shorter downward phases in the "operating (results) cycle". Perhaps the downward phase in the present cycle will already give an answer on the impact of this development.

\subsection{Secondly: Globalization - what is new about it and what it has led to in reinsurance and insurance as the latter's client-base}

The second fundamental change affecting the insurance and reinsurance industry is the trend towards increasingly global markets for a growing number of products and services and thus industries. Looking at the effects on reinsurance and insurance, one has to differentiate.

- Reinsurance, almost since its inception, has always been (of necessity) global, or what this meant in earlier more Eurocentric days.

Geographical spread, as a means of balancing large risk exposures and thus being able to offer larger reinsurance capacities, has always required a multinational or even global approach. Analysing the more recent developments, we see globalization assuming a new dimension.

The most indicative illustration is that until a few years ago US reinsurers operated largely only locally and, considering their huge domestic market, could afford to do so. 
Conversely, a reinsurer that was the number one or two worldwide did not need to be the number one or two in the US as well. When a few years ago the US reinsurers started to take a much more global strategic approach and acquired globally operating reinsurers, this situation changed. An optimal geographic spread, or in more general terms, an optimal reinsurance portfolio today requires any global reinsurer to have a sufficiently large US portfolio balancing his overall risk and thus earnings potential.

Globalization thus gives the size of a reinsurer today a very different value. In a global financial world size and thus also premium income determines financial strength, security, investment earnings, underwriting and service capacity and thus business opportunities. 'This has inevitably led to the creation of a few "mega" reinsurers (as yet, however, leaving adequate room for niche reinsurers, i.e. product or regional specialists).

- Globalization in insurance, the client-base of reinsurance, continues to develop strongly: It has manifold reasons and varying consequences for reinsurance.

Very large industrial risks are increasingly being placed with very large internationally operating insurers - and reinsurers. In many smaller markets local insurers have neither the capacity nor the expertise to cater for this risk segment, for which a largely global market has thus developed. Increasingly "alternative markets" - mainly reinsurers offering their capacity and services to captives and risk managers - are also operating in this field.

Many international industrial concerns, as original risk carriers, seek globally operating insurers - and reinsurers.

But apart from these large risk segments, insurance still widely remains local, requiring locally based insurers, particularly for personal lines and smaller commercial and industrial business.

An insurer wishing to operate globally also in these smaller risk fields needs to be locally represented in the same way as a purely local insurer. Operating globally in these fields - and this also makes it attractive for global insurers, who are increasingly entering this field - will allow certain global synergies and economies of scale in product and service development, in IT infrastructure, in training, in research and development (even if these synergies and economies of scale have intrinsic limits, in today's communication age these may be extendable).

- Geographic portfolio optimization through global operations is achievable as regards the effects of large losses and catastrophes, i.e. the "risk of good or bad luck" in a portfolio (also called the "risk of random fluctuations"). Portfolio optimization through geographical diversification is, however, becoming less and less achievable for the effects of so-called "risks of change" (unexpected political, economic, social, technological or competitive developments). This is due partly to the increasingly parallel developments of truly global classes of business in global cycles, but also to the increasingly parallel cyclical behaviour of classes of business with a more local character. This again is due to national economies growing together, becoming interdependent and thus developing increasingly in parallel. 
In this context we have to see that in many fields reinsurance is behaving cyclically in a very global way, thus affecting where needed also more locally developing classes of business. That adverse rates and conditions in one market (due to "risks of change") are thus balanced by favourable rates and conditions in others, becomes less and less likely. Really only personal lines business, needing little or no reinsurance, might in the future provide optimal geographical relief between markets - which is a good reason for an international insurer to take a global approach also in these lines.

- It will be interesting to watch the impact of electronic commerce, especially through the Internet, on insurance and reinsurance. It is quite foreseeable that simple types of insurance with easy-to-settle claims might increasingly be offered and purchased through such media. More complex risks could equally be offered and purchased through such media if trading took place between globally present partners, such as internationally operating brokers, insurers and reinsurers, well acquainted with the way they do business or agreeing "standards" for this (which they already do).

- An aspect not to be neglected in the context of globalization is that this development has also been taking place amongst the original risk carriers and/or insureds, in many industries even earlier and more intensively than in insurance. Internationally operating industrial conglomerates and financial institutions are becoming larger and larger and retaining more and more of their risks and thus, in "a flight to quality", are insuring - or reinsuring through captives - increasingly only with insurers or reinsurers of equivalent financial strength. This is making the very large risk segments a global playing field for an increasingly smaller number of very large insurers and reinsurers. This development is reflected in the unprecedented consolidation process that has been taking place for some time amongst particularly large insurance brokers, insurers and reinsurers.

- The consequences of all this for reinsurance supply and demand are manifold. The consolidation process in insurance, in the dimension in which it is taking place today, creates insurance groups of a size which will purchase comparatively little traditional reinsurance, considering their own large retention capacities and thus reduced reinsurance needs, particularly for small and medium sized risks, but also for large risks.

Reinsurers are thus evidently subject to a "compression scenario" (as Matthias Haller has called it): The smaller risks, at least if written by large insurers, are reinsured to a lesser and lesser extent; the field of large risks is increasingly becoming one in which only the large internationally operating insurers, who reinsure little, compete. Internationally operating reinsurers who want to play a role in this large risk field are therefore to an increasing extent almost compelled to compete directly as "alternative markets" with major international insurance groups - who equally almost all provide not only insurance and financial insurance but also reinsurance and financial reinsurance. In these alternative markets it becomes increasingly meaningless whether formally insurance or, through captives or fronting insurers, reinsurance is placed.

A reinsurer can avoid this compression scenario only in lines and markets where insurance is carried out in a more local manner and more by local insurers, who need his capacity and services - also and specifically in the face of competition from internationally operating insurance groups. 
- Therefore, much more than in the past, an internationally operating reinsurer needs to be client-segment-oriented, in its strategy, its products, its services and thus the range of expertise it offers.

For the globally operating multinational insurance groups that are its clients, it needs to have available the large capacity and the sophisticated specialized services and expertise wherever they need them.

For its clients operating only or mainly locally, the reinsurer needs to have a broad range of services available locally to help them survive against local and global competition and thus maintain them as clients.

\subsection{Thirdly: The process of deregulation in financial services as a whole, not only insurance, and what it has changed and is still changing}

Reinsurance, because it does not deal with the public and because of its necessarily global approach, has always been much less regulated in most countries than insurance and other financial services. Deregulation in the sense of freedom of reinsurance thus always existed in most markets, with only few requiring from foreign reinsurers licences, deposits or local investments. Only a small and diminishing number of countries still restrict foreign reinsurers through national reinsurance monopolies or through obligatory reinsurances with national or regional reinsurers.

Deregulation in insurance, as opposed to reinsurance, has been a development of the last few decades in most countries. Most countries in the past limited insurance activities to local insurers and thus more or less restricted the activities of foreign insurers, not only for operations from outside, but also for operations from inside a market through foreignowned branch offices or subsidiaries (by, for example, not allowing foreign majority holdings).

Deregulation of insurance, in the sense of a market-economy-oriented liberalization of products and pricing, is a development which has occurred in most markets only in recent decades. Only a few insurance markets in the past did not regulate the selling of insurance products and the way prices had to be calculated and offered. This is not the place to go into the reasons why this was the case and whether the extent of regulation was determined by the interests of the insurance buyers only or also by the interests of the insurance sellers.

What we see today is that, in line with the GATT and now the WTO philosophy and rules, insurance products and prices in most markets have increasingly become or are becoming deregulated.

A look at the consequences of this in the insurance markets, as the client-base of reinsurance, and thus at how reinsurers are affected and have to adjust shows that there are manifold impacts - many not due to deregulation only, but due also to globalization.

- Deregulation means more freedom in competition (within a market and from outside) as far as products, policy terms and conditions, prices and services are concerned. The resulting increased competition favours the buyers and reduces the profit margins of the sellers. This for the reinsurer in the long term has a distinctly positive aspect: if 
competition reduces the profit margins of insurers, it also reduces their ability to absorb fluctuations in their results and thus makes reinsurance more necessary for all insurers (the smaller ones more, the larger ones less) to produce optimal results (not affected by unnecessary fluctuations) for shareholders, capital markets and analysts. In the short term, when a previously protected insurance market is transformed into a competing market, the process of deregulation is likely to lead to initial underwriting losses, if not operating losses, owing to the learning problems in coping with a new environment, the lack of instruments to control results and to price risks. This will likewise affect the reinsurer's short-term results. In the medium to long term, however, a market economy, to which deregulation leads, is the optimal legal environment also for reinsurance.

- Even if deregulated insurance markets still allow a certain cooperation between insurers in associations (for data collecting and for legal questions), they lead to the disappearance of market-dominating insurance associations and reduce these largely to trade organizations representing the insurance industry in matters of common concern vis-a-vis the public and government bodies. Whilst insurers in the old regulated, insurance-association-determined days tended to act collectively and saw their joint collective interests as being the same as their individual interests, they do not do this any longer. Particularly large insurers in most deregulated markets today are guided little, if at all, by collective interests, but instead by their individual interests. These they develop largely irrespective of the interests of their competitors, particularly the smaller ones. Even if they are prepared still to participate in the remaining activities of insurance associations, they will increasingly do this only to the extent that it does not conflict with their individual strategies and tactics. This has implications for underwriting and operating results: it is foreseeable that overall market results will become less meaningful compared with the results of the individual insurers. These will at the same time be less comparable than in the collective past and will instead distinguish the individual companies' strategies and performances from those of their competitors.

- For the reinsurers, the above developments have had decisive consequences: Whereas in the past they could largely follow market conditions and prices and rely on their client insurers to balance good and bad times, also for them, they cannot do this any more. Reinsurers thus usually can no longer provide reinsurance in a market at uniform market terms, i.e. at terms of trade, at conditions and at reinsurance prices which are more or less the same for all their client insurers in a market, at most differentiated by profit commissions and loss participations. Reinsurers today, in contrast, have to realize that the portfolios they receive in reinsurance from their various clients differ so greatly in their risk and profit potential that they have to give up any market approach in favour of a clear client approach. They have to conclude with each client terms commensurate with its particular reinsured portfolio, its risk profile, its profit potential. If they seemingly treat one client better than another, this may only reflect different risk profiles and profit potentials.

- This in turn has another significant consequence: In the past reinsurers only had to calculate their own prices in non-proportional reinsurance. Reinsurer today, in most markets, must not only realize that in proportional reinsurance they can no longer just follow a market rate level; they must also realize that their clients will reinsure only certain segments of their portfolios, which might not follow their overall portfolio price 
level. Therefore in proportional reinsurance, too, reinsurers have to price the reinsurance protection they are giving on the basis of the specific portfolio or risk segments they reinsure out of their individual clients' overall portfolios.

This means that reinsurers have to have pricing instruments - today software programs both for proportional reinsurance and for non-proportional reinsurance. The information they need to base their pricing on for a reinsured portfolio segment may in the future, if such information becomes available in electronic form, even be obtained on an individual risk basis.

When negotiating the price for proportional reinsurance with clients reinsurers must - as in non-proportional reinsurance - "detach" themselves from the original rate level applied by the client and agree the price needed for the reinsured portfolio segment. There are various reinsurance technical instruments to do this: the price can be adjusted by reductions in the commissions paid to the reinsured; the reinsurer can also make the client participate in each reinsured claim with an artificial loss deductible; and the client may have to concede loss participations. In the future, if electronic data exchange allows, reinsurers could fix the price for their protection even for whole reinsured portfolios on an individual risk basis.

- In a deregulated liberalized climate the traditional roles in any one industry will change. A strictly regulated environment encourages clear functional divisions of labour, whilst a breaking down of regulatory restrictions opens the market participants' interest for doing things which in the past were done by other market participants. This has long been evident in the insurance and reinsurance industry. Brokers are managing insurance and reinsurance companies (captives, but also others) on behalf of their clients, and also on their own behalf. Insurers are active in reinsurance to a larger or smaller extent; there is hardly a large international insurer which is not also a reinsurer in its own right - and not just as a group internal reinsurer. And the reverse is true for reinsurers who, in the compression scenario in which they find themselves are - as I have already said - almost bound not just to provide traditional reinsurance but also to go into insurance and financial insurance for the large risk segment. This they cannot just leave to the major international insurers, who reinsure increasingly little. They instead need to obtain their share in this large risk segment in other ways - which will mean not only through insurance and financial insurance but also through risk management services in the widest sense. Reinsurers can obtain their share of the small and medium-sized risks, particularly in personal lines business, which is reinsured to an increasingly small extent, by becoming also direct insurers for these risk categories. So, more and more we will see groups developing which are equally active in insurance and reinsurance.

- It is also foreseeable that functions which in the past were clearly divided between brokers and consultants on the one hand and insurers and reinsurers as risk carriers on the other will increasingly be performed by all three, be it in the field of consulting, servicing (also for fees) or broking (of risks which insurers or reinsurers for whatever reason do not want to carry themselves, but for which they may wish to organize cover for their clients). The idea behind this is that it is becoming increasingly important, if not imperative, to cater for all one's client's needs in the field of risk management and other risk-related consulting and service activities, asset management, broking, etc. in a 
comprehensive way and not just in certain fields, leaving the others to competitors, who might then grasp more than one would like them to.

- Deregulation of any one trade, such as insurance in the overall context of financial services, also means that the traditional border lines between this industry (and its participants and functions) and its neighbouring industries become blurred, if not open to all industries which are active in neighbouring fields.

Insurers and banks assume certain risks of their clients: the insurer when it deals with its clients' risks, the bank when it allows its clients by means of credit to operate on a much larger scale than without third party finance. And when banks sell "catastrophe options" and "futures", they are also obviously in the risk assumption business.

As insurers, particularly life insurers, are also asset managers for their clients, it is thus almost bound to happen that the capital markets, banks and fund managers try to compete with the insurance industry for their clients' savings and vice versa.

Investors are potentially interested in also investing in risks as a means of diversifying their investment risk and at the same time opening up a new field of activities for themselves: investment in "securitized" risks. So it appears almost logical that the capital markets will try to compete with insurers and reinsurers in assuming risks by investing in them. The fact that the capital markets have not yet achieved a signifant breakthrough in offering securitization of risks does not mean they have no potential. In fact, there are various reasons why the breakthrough has not yet occurred: Insurers assume risks on the liabilities side; this relieves the balance sheet of their clients also on the liabilities side; the capital markets have to overcome the problem that they assume risks on the assets side, which needs to be transformed into a protection of clients' balance sheets; insurers are also used to the instruments, the language, the procedure when protecting themselves by means of reinsurance and are not yet correspondingly familiar with buying protection from the capital markets. The capital markets are also confronted with a risk management expertise in insurance and reinsurance that is difficult to match. So it is too early to say to what extent the capital markets with their huge potential capacity might substitute the reinsurance and insurance markets. It is, however, more likely than not that the capital markets will provide at least supplementary protection for risks that are very large and difficult to insure, particularly in "harder" periods in which the capacity of the reinsurance and insurance industry may contract due to unfavourable results and insurance and reinsurance prices may not be as low as in "softer" periods.

\subsection{Consequences: a changed client-reinsurer relationship}

As we have seen, the three fundamental changes have significantly changed the client-base of the reinsurer, its demand for reinsurance or, in today's terms, the addedvalues demanded from reinsurers, the way in which reinsurers have to approach their business and, through all this, the nature of the insurer-reinsurer relationship. Many aspects of this have already been touched on. Summarizing these and looking at them from an overall perspective, the following can be said.

- Reinsurers have to take a much more client specific, client-orientated approach. Every client will expect his reinsurer to deal with him irrespective of how he deals with his 
competitors (except in very fundamental questions). Reinsurers cannot and will not deny a good client what they quite rightly might deny a not-so-good client in the same market, which in the old days of a market-oriented approach was possible and often unavoidable.

- Reinsurers have to realize that clients reinsure for a variety of different motives, of which protection against the risk of ruin may not be the most important. In the decision of an insurer as to what and how much to reinsure, the operating profit potential of the line of business and the reinsured portfolio today and in the near future plays a significant role. Insurers increasingly protect their overall results by selecting for reinsurance the risk segments which benefit the overall net performance in the best way. This is a perfectly legitimate "antiselection" against reinsurers, who have to accept this, but naturally have to consider it in their pricing, in their terms and conditions.

- Today it is much less often a long-term partnership with a reinsurer which an insurer is looking for, but more a short-term oriented decision to participate in a certain risk or risk segment at a price and at terms to be negotiated for a certain period with little or no obligation to make good an unfavourable or too favourable outcome. A "sharing of fortunes" in a sense which Klaus Gerathewohl still thought widely possible (in 1988 in his contribution to a series of essays in honour of Dr. Horst K. Jannott's 60th birthday) is, I believe, increasingly pursuable only in a relationship which is understood by both sides as a partnership of truly "shared fortunes". This means that reinsurers must expressly demand a balancing of results over a certain period where they are expected to assume risks which in their view may leave them with a loss rather than allow them a fair chance of a profit. These would be situations in which today aspects now common in financial reinsurance might better be applied than the instruments of more traditional reinsurance.

- Segmentizing the activities of a reinsurer, one could (as Klaus Gerathewohl did in the essay mentioned) differentiate between various scenarios: one in which reinsurers assume risks at definite terms and conditions which they will try to balance within their own global portfolios and for which they would not attempt to have an adverse result made good by a client. Conversely there would be reinsurance contracts, particularly financial reinsurance contracts, with limited-loss ("finite risk") and profit potentials and corresponding obligations to correct unexpected losses or profits. In between we would have the segments where the reinsurers and their clients have to determine - and should do so openly - whether such contracts are to be seen in the context of a partnership in which a sharing of fortunes over time is aimed at by both sides. In such a partnership, if desired, both sides might be prepared to correct results at least prospectively which deviated from what was jointly expected. The more, however, reinsurers detach themselves from the original client's prices and conditions, the more likely it is that this middle segment will become smaller and the other two larger.

- Reinsurers will thus need to adjust their approach to the reinsurance-buying philosophy and practice of their clients. The more "antiselective", or neutrally put, the more segmental and short-term the client is in buying reinsurance, the more reinsurers also have to apply a short-term approach, not leaving their fortunes in the future, but seeing to them exclusively in the contract period for which they are committed.

- Reinsurance buyers increasingly no longer demand standard products and services from their reinsurers, but client-oriented tailor-made ones. They look for solutions rather 
than products in the old sense, which may combine traditional reinsurance, financial reinsurance and even incorporate securitized elements from the capital markets and take into account not only risk-related aspects, but also balance-sheet, profit-and-loss account and thus tax-related aspects. These solutions may be multi-line and multi-year. In their financial reinsurance or securitized elements, they may also go beyond the traditional borders of insurability and reinsurability.

- To keep clients and gain new ones, reinsurers therefore have to gear their internal structures and expertise to these diverse demands: They must be able to professionally assist their clients in the most general and in the most specific ways (not necessarily through the same persons); they must consider their clients' needs from the broadest multiline, bottom-line balance-sheet and tax-oriented perspective and at the same time in the most detailed risk-specific context (again very likely not through the same persons). Reinsurers' expertise will thus have to go a long way beyond insurance and reinsurance, the relevant services being provided either by their own experts or in cooperation with third parties, e.g. banks.

The challenge for reinsurers is to be able to provide these general and specific services in a quality which even their large clients cannot produce themselves or not with the same broad range - which is the international reinsurer's potential strength.

Wherever reinsurers have to deal with large individual risks, be it in a relationship with an insurer or a captive or an industrial client, they will need to have experts for this who are at least as good as those their clients have in house.

It is likely that the people in a reinsurance company who look after the very large clients in one country will be the ideal ones to also deal with the very large clients and their problems in other countries. Conversely the ones who dealt with smaller and mediumsized companies in one country are likely to be most useful for similar companies in others.

\section{Looking Forward: The Likely Future of Reinsurance and Reinsurers - A Few Thoughts Only}

How difficult it is to predict the future, we realize, when looking at how we got to where we are now and where, in this complex network of various determinants, reinsurance and reinsurers stand today. When trying to think about - rather than attempt to predict - how this industry and its participants will develop in the future, which directions they may take and which they may not, one can only try to draw conclusions from where we are now and where a certain logic indicates the direction of future development. Let me try.

- Anticipating the future demand for reinsurance has been a controversial issue over all recent decades. There were reinsurers who at times were bearish in this respect whilst others were bullish. This often reflected decisions they had to take then, which could be backed by a bullish or bearish view on reinsurance.

What may be a surprise to many is that the percentage share which reinsurers have assumed worldwide from non-life insurance in terms of premium has stayed almost 
unchanged somewhere around $15 \%$ over the last few decades (in life it was and is much lower). Obviously the negative impacts on the global demand for reinsurance (consolidation amongst insurers, growing insurers and thus fewer and larger insurers who reinsure less) - have been compensated by positive ones: new industrial countries and new emerging markets, new risks, increasing single risks and ever-higher catastrophe risk exposures, as shown by the natural catastrophes between 1989 and 1994; liberalization, deregulation, globalization resulting in increased competition and thus favouring rather more than less reinsurance; discouraged or reduced crosssubsidization of industrial business from personal lines impacting positively on the reinsurance of industrial business; capital markets and investment analysts pursuing shareholder value concepts penalizing unnecessary fluctuations of results and thus impacting positively on reinsurance demand. In this context one should bear in mind that also in the future even the largest insurance groups will tend to buy more rather than less reinsurance or financial reinsurance - or perhaps securitized products - in order to protect their return on equity against risks for which they can buy protection.

Reinsurance premiums in industrial business may stagnate or come down (reflecting a similar development in insurance, with insurers being affected by increased selfretentions amongst their insured clients, by improved risk management and loss prevention leading to a reduction of the overall amount spent on insurance). This, however, does not necessarily mean that reinsurers' share of the overall industrial risk will become smaller - even if more low-premium-volume non-proportional reinsurance as opposed to higher-premium-volume proportional reinsurance is purchased, which is the trend.

Assuming that development continues to go in this direction, it is likely that positive impacts on demand for reinsurance will continue to compensate for negative impacts. So there is good reason to assume that the risk share which reinsurers obtain from global insurance will remain relatively unchanged, at least in the next few decades. At the same time it is likely that increasingly reinsurers - and this in future also in the Third World will get less of the personal lines business, of the small and medium-sized business (which by the way in the last few decades has grown faster than the industrial and commercial risks and will continue to do so in the future).

- This means that reinsurers' business, with less basic business, will continue to become less balanced, that it will be even more exposed to potentially larger fluctuations due to major losses and catastrophes in the future. This requires even more risk expertise and reinsurance technique, more experts than today - and is also an argument for diversifying into direct insurance, in both the large-risk as in the small- and medium-risk segments.

- In competing with smaller reinsurers, the large reinsurers will benefit from their superior security, from their international experience, their larger network of experts and service capabilities, provided they do not act as a conglomerate of local reinsurers but as global players using their global strengths and synergetic potentials to the utmost. This will allow the large reinsurers to be, with various centers of competence, the "multispecialists", which they need to be to compete with their large international competitors as well as with the specialist niche reinsurers. 
- The consolidation process not only amongst insurers but also amongst reinsurers will continue, as the reasons for it will prevail. Thus in reinsurance - as is likely in insurance for the large-risk segments - an "oligopolistic" situation is developing, with a small number of "mega" reinsurers with an increasing overall market share (today already over $40 \%$ ) beside a decreasing number of medium-sized and small reinsurers. This, however, will not reduce competition, as for most risks more than enough reinsurance capacity will be available. Most likely this development may even increase the fight for market share in the various product lines and regions, particularly amongst the large reinsurers. Given the shareholder-value orientation of the large reinsurers, however, it may increasingly be service and not just price that becomes the field for competition amongst them.

- In this competitive environment the traditional divisions of labour between market participants in insurance and reinsurance will increasingly disappear. More than today the future players will probably be simultaneously insurers, reinsurers, consultants and brokers in order to cater comprehensively for the potential risk management needs of their clients. They must at least be able to offer such comprehensive services even if clients buy what they need from various, albeit fewer, suppliers - in a "flight to quality". In this context it is not unlikely that the very large insurers - and reinsurers will buy selectively, maybe even "unbundled", rather than across-the-board from one seller. The medium-sized and smaller buyers may prefer to put themselves more into the hands and care of a few larger reinsurers, if not only one partner again a flight to quality.

- In our increasingly competitive environment, it is probably a truism that the potential buyer will only buy what somebody else can provide better, with more expertise and faster than he can himself, and that he will buy from the one who is better in quality compared with his competitors. This approach will very likely determine even more the behaviour of the very large buyers, be it the original potential insurance buyer or the potential reinsurance buyer. As far as the very large international insurers, who are mostly also reinsurers, are concerned, their reinsurers will thus have to compete with their clients increasingly high internal expertise. Reinsurers therefore will have to be at least as good as, if not better than, their large clients in order to be successful.

In competition with the in-house expertise of their clients and their large competitors' expertise, it will be the resources and the expertise developed with these resources which will determine the future of any one reinsurer. Optimal client- and expertiseoriented structures, superior research and development, and superb internal training are indispensable in order to be better and offer more value as a reinsurer, as a service provider, and as a consultant when competing with client-internal competition and external competition.

- The large international reinsurers, being more broadly involved in insurance and reinsurance worldwide, are likely to maintain their important function of an "earlywarning" and security system for our industry as a whole. In a future world which will be even more a world of growing risks to economies, to societies, to industry, to business and individuals, reinsurers may thus continue to play their outstanding role as a kind of global risk-manager league - for their own benefit, for the benefit of their clients and for the benefit of the clients of their clients, our global society. 